\title{
CALAPPA SULCATA RATHBUN (CRUSTACEA, DECAPODA, CALAPPIDAE) DE GUARATUBA, PARANÁ, BRASIL ${ }^{1}$
}

\author{
Isabel Takeko Nakamura ${ }^{2}$ \\ Jayme de Loyola e Silva ${ }^{2,3}$
}

\begin{abstract}
CALAPPA SUlCATA RATHBUN (CRUSTACEA, DECAPODA, CALAPPIDAE) FROM GUARATUBA, PARANÁ, BRAZIL. A concise description and a latitudinal distribution to South Brazil of Calappa sulcata are presented.

KEY WORDS. Calappa sulcata, Crustacea, Calappidae, Paraná, Brazil
\end{abstract}

Embora tenha havido, através do Convênio SUDEPE/UFPR, entre os anos de 1967/77, um intenso controle de desembarque do pescado, em todo o litoral do Paraná, jamais constatou-se, neste período, a ocorrência de Calappa sulcata Rathbun, 1898. Somente, em dezembro de 1983 foi coletado um exemplar macho na baía de Guaratuba, Paraná.

RATHBUN (1937) estuda os gêneros e as espécies, então conhecidos, da família Calappidae, e descreve oito espécies de Calappa Weber, 1795 das Américas.

HOLTHUIS (1958) trabalhou com várias coleções de Decapoda de West Indies e da América do Norte e descreveu três espécies novas de Calappa.

HOLTHUIS (1959) relaciona as localidades de coleta, suas latitudes e longitudes, tipos de substrato, estágios de crescimento dos espécimes do Suriname.

WILLIAMS (1965) publica artigo sobre Decapoda das Carolinas, com chaves e diagnoses de quatro espécies do gênero Calappa.

FAUSTO FILHO (1967) descreve quatro espécies de Calappa do norte e nordeste do Brasil.

NAKAMURA \& LOYOLA E SILVA (1985) comunicam em Congresso a ocorrência de C. sulcata, pela primeira vez, para o litoral do Estado do Paraná, Brasil.

MELO et al. (1989), referem-se a distribuição, desde Carolina do Norte até o litoral do Estado do Paraná, salientando o aumento do limite meridional da espécie.

1) Contribuição número 743 do Departamento de Zoologia, Universidade Federal do Paraná.

2) Departamento de Zoologia, Universidade Federal do Paraná, Caixa Postal 19020, 81531-970 Curitiba, Paraná, Brasil.

3) Professor Senior e pesquisador do CNPq. 

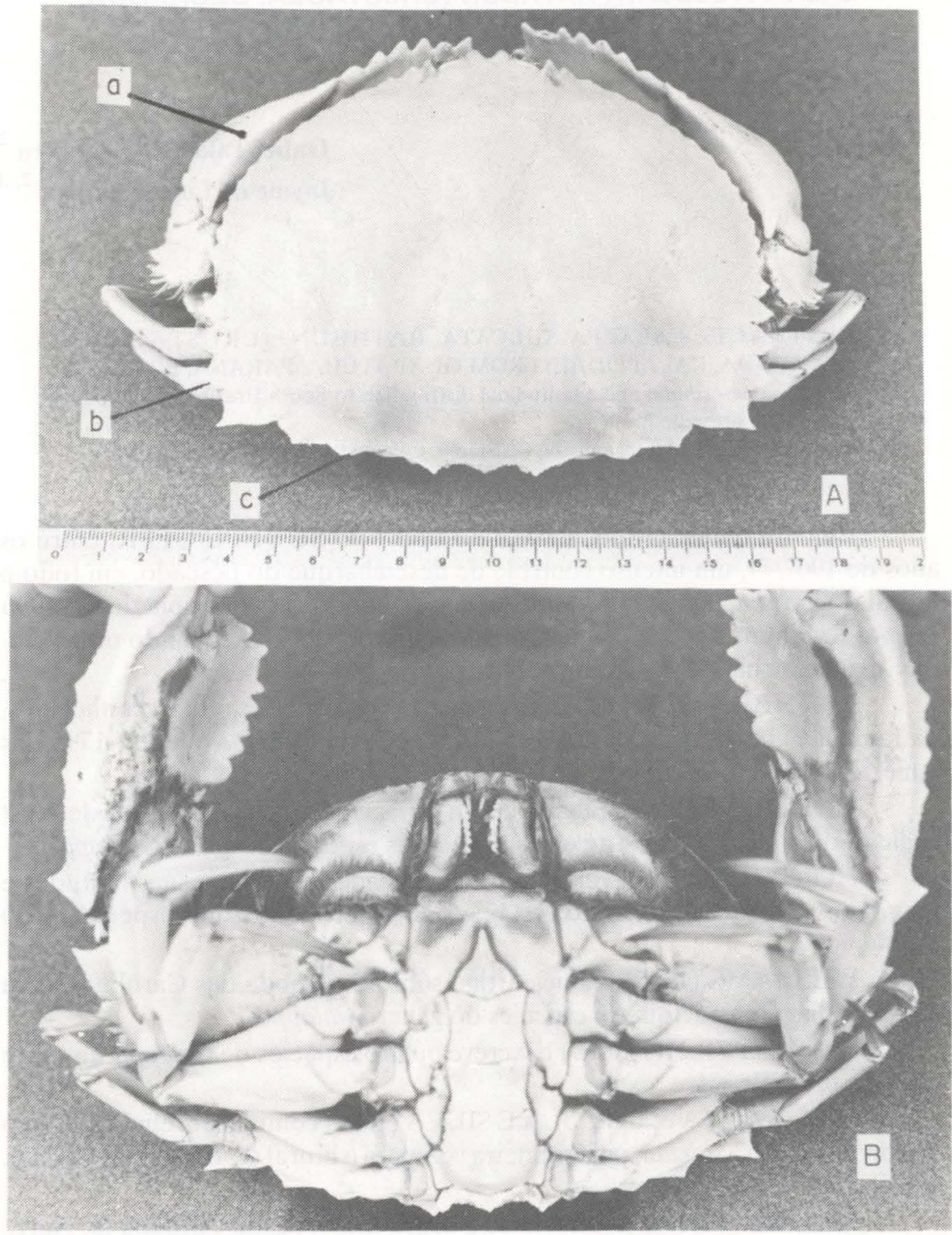

Fig. 1. Calappa sulcata Rathbun, 1898 (macho). (A) Vista dorsal; (a) quelípodos laminados; (b) espinhos póstero laterais; (c) espinhos da margem posterior; (B) vista ventral.

O presente trabalho tem por objetivo confirmar a ocorrência de Calappa sulcata no litoral paranaense, descrever sucintamente e ampliar a sua área de distribuição para o sul do Brasil (2553'S). 


\section{Calappa Weber, 1795.}

Diagnose: Carapaça fortemente convexa, arredondada na frente, provida posteriormente de um par de expansões alares laterais, sob as quais as patas ambulatórias são escondidas, quando flexionadas. Fronte pequena, bilobada. Órbitas pequenas e circulares. Pedúnculos oculares pequenos e grossos. Quelípodos muito grandes, protegendo a parte anterior do animal. Mero apresentando externamente, e próximo à extremidade distal, uma expansão alar transversal. Palma, fortemente comprimida, tendo no seu bordo superior, uma crista denteada. Abdome, no adulto, com o terceiro, quarto e quinto segmentos fusionados. (Rathbun, 1937).

\section{Calappa sulcata Rathbun, 1898}

Figs 1 e 2

Calappa sulcata Rathbun, 1898: 289, pl. 9, figs 3,4. - Hay \& Shore, 1918: 422, pl.31, fig. 6. - Rathbun, 1937: 211, pl.64, figs 7, 8, pl. 65, fig. 1. - Holthuis, 1958: 179, figs 51-54. - Holthuis, 1959: 166. -Williams, 1965: 155, figs 135, 136. - Fausto Filho, 1967: fig. 3, est.II, 5, 6. - Nakamura \& Loyola e Silva, 1985: 71. - Melo, Veloso \& Oliveira, 1989: 4.

Descrição: Carapaça de contorno ovalado, com a superfície dorsal convexa no sentido póstero-anterior, com cinco elevações convergindo longitudinalmente para frente, cada uma com uma série de pequenos tubérculos. Asas póstero-laterais da carapaça reduzidas, com quatro espinhos nítidos e agudos, diminuindo de tamanho no sentido póstero-anterior, e seguindo como granulações pequenas, até a fronte. Margem posterior com oito espinhos nítidos, sendo os dois angulares, salientes e agudos. Largura da carapaça pouco maior que o comprimento. Fronte com dois dentes submedianos (Fig. 1A).

Palma de forma triangular, larga, forte, escudal, servindo para proteger toda a parte anterior do animal. Crista superior da palma com oito espinhos fortes; face anterior com duas séries convergentes de espinhos que se encontram com um forte espinho basal. Dedos dos quelípodos, direito e esquerdo, com dentes completamente diferentes (Fig. 2A). Mero, no lado direito, subdistalmente, com aba na parte externa provida de cinco dentes agudos; no lado esquerdo, o segundo e o terceiro dentes fusionados (Fig. 2B).

Margem inferior do mero, de todos os pereiópodos, serrilhada, com aspecto de quilha. Machos com abdome estreitado. Segundo segmento abdominal com série transversa de pequenos tubérculos pontiagudos. Terceiro, quarto e quinto segmentos abdominais inarticulados, mas com suturas. Telso triangular, com ápice pontiagudo (Fig. 1B).

Cor bege-róseo, antes da fixação. Esta cor desvanece, quando transferido para o álcool $70 \%$ e, então a parte ventral torna-se bege-amarelado e a dorsal, róseo-claro.

Comprimento da carapaça $93 \mathrm{~mm}$ e largura $130 \mathrm{~mm}$. Maior largura do quelípodo $66 \mathrm{~mm}$.

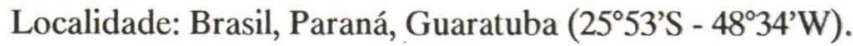



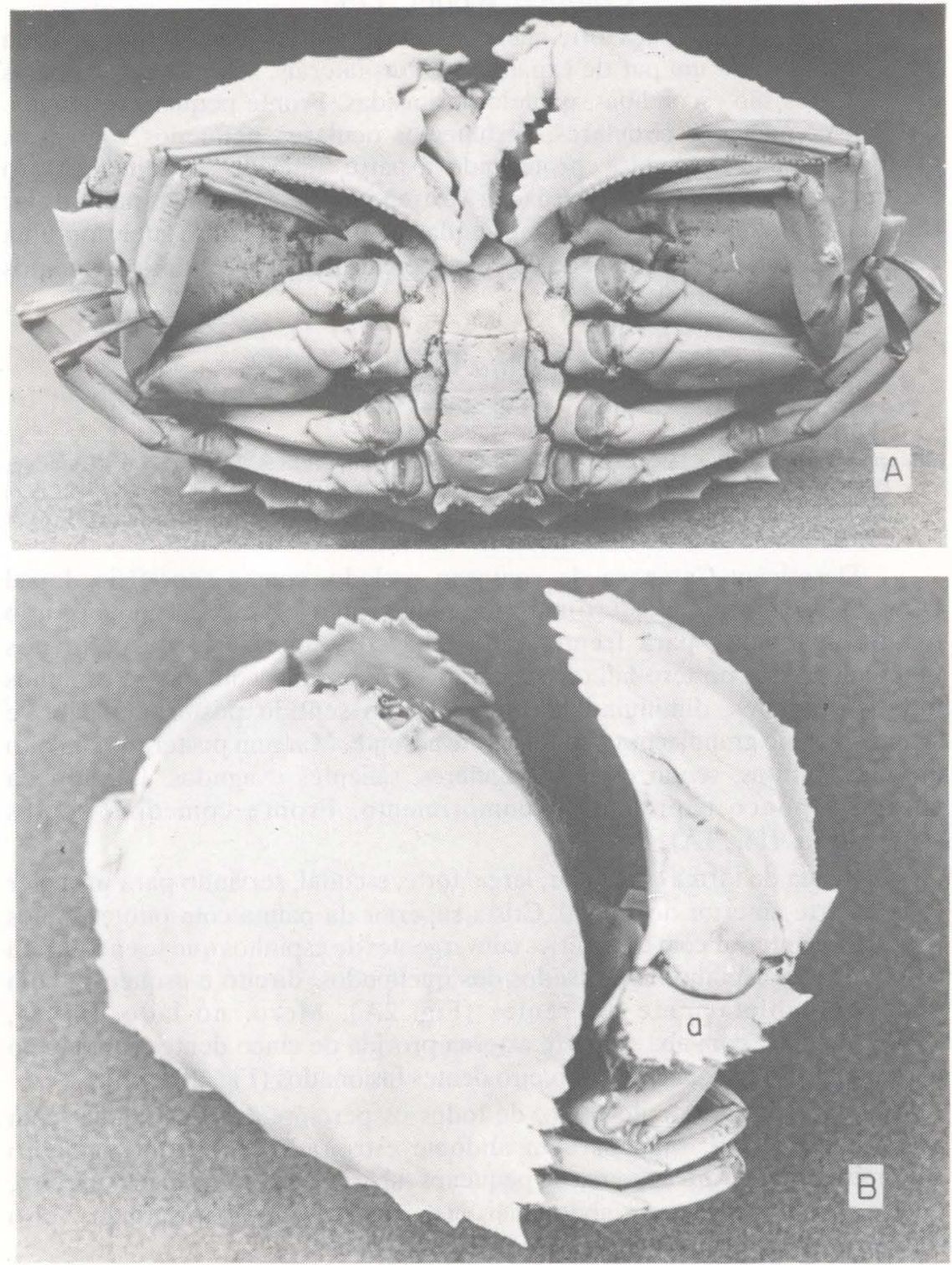

Fig. 2. Calappa sulcata Rathbun, 1898 (macho). (A) Quelípodos em vista frontal; (B) vista dorso-lateral; (a) mero direito com aba denteada.

Distribuição: Estados Unidos: Carolina do Norte, Flórida, Lousiana e Texas. México: Golfo do México. Porto Rico. Suriname. Venezuela: Ilha Margarida. Brasil: Amapá, Pará, Ceará, Sergipe e Paraná. 
Notas ecológicas: de acordo com Melo et alii (1989), C. sulcata habita "águas rasas até $80 \mathrm{~m}$, tendo preferência por fundos de lama". Segundo FAUSTO FILHO (1967), "C. sulcata é comum nos bancos camaroneiros do norte do Brasil, sendo facilmente capturada pelos arrastões-de-porta, em profundidades que variam, de 60 a $80 \mathrm{~m}$ e de 89 a 100 milhas da costa". HOLTHUIS (1958), de inúmeras coletas entre West Indies e América do Norte, registra esta espécie para profundidades que variam de 36 a $164 \mathrm{~m}$ e de 1 até 30 milhas de distância da costa. WILLIAMS (1965), para exemplares coletados nas Carolinas, indica o mínimo de $12 \mathrm{~m}$ e o máximo de $210 \mathrm{~m}$, e que, raramente ultrapassa esta profundidade. Segundo RATHBUN (1937), em exemplares coletados entre Carolinas e West Indies, houve variação desde 22 até $64 \mathrm{~m}$ de profundidade, em fundos areno-lodoso, conchas quebradas e rugoso.

Não se pode dizer que no litoral do Paraná, $C$. sulcata, nunca tenha sido capturada, porém jamais se teve conhecimento. Possivelmente, a dificuldade de encontrá-la, seja devido a preferência por profundidades mais acentuadas e distantes da costa, fora da área de atuação dos pescadores artesanais, que é no máximo de $10 \mathrm{~m}$ de profundidade. Sabe-se que espécies que vivem em maiores profundidades podem ser trazidas para as praias, quando em marés de sizigia, ou mesmo com fortes vendavais. A partir de 1983, quando da coleta do único exemplar de $C$. sulcata, no litoral do Paraná, fez-se verificações junto às colônias de pescadores, mostrando o exemplar, e as informações obtidas sempre foram negativas.

\section{REFERÊNCIAS BIBLIOGRÁFICAS}

FAUSTO FILHO, J. 1967. Sobre os calapídeos do norte e nordeste do Brasil. Arq. Est. Biol. Mar. Univ. Fed. Ceará, Fortaleza, 7 (1): 41-62.

HOLTHUIS, L.B. 1958. West Indian crabs of the genus Calappa, with a description of three new species. Studies on the fauna of Curaçao and other Caribbean Islands, 8: 146-186.

- 1959. The Crustacea Decapoda of Suriname (Dutch Guiana). Zool. Verhand., Leiden, 44: 1-296.

MELO, G.A.S.; V.G. VELOSO \& M.C. OLIVEIR.A. 1989. A fauna de Brachyura (Crustacea, Decapoda) do litoral do Estado do Paraná. Lista Preliminar. Neritica, Pontal do Sul, Paraná, 4 (1-2): 1-31.

NAKAMURA, I.T. \& J. LOYOLA E SILVA. 1985. Espécies de Calappidae do litoral do Paraná. Resumos do XII Congr. Bras. Zool., Campinas, São Paulo, p. 71.

RATHBUN, M.J. 1937. The Oxystomatous and allied crabs of America. Bull. U.S. Nat. Mus., Washington, 166: 1-278.

WILLIAMS, A.B. 1965. Marine Decapod Crustaceans of the Carolinas. Fish. Bull. Washington 65 (1): 1-298.

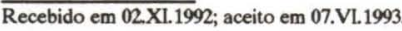

